\title{
Online Third-Order Liquid Chromatographic Data with Native and Photoinduced Fluorescence Detection for the Quantitation of Organic Pollutants in Environmental Water
}

Rocío B. Pellegrino Vidal, Alejandro C. Olivieri, ${ }^{\circledR}$ Gabriela A. Ibañez,* and Graciela M. Escandar*®

Instituto de Química Rosario (CONICET-UNR), Facultad de Ciencias Bioquímicas y Farmacéuticas, Universidad Nacional de Rosario, Suipacha 531, 2000 Rosario, Argentina

Supporting Information

\begin{abstract}
Third-order liquid chromatographic data were generated online for the simultaneous quantitation of six organic environmental pollutants. The employed strategy consists in reducing the linear flow rate at the column outlet. A postcolumn UV reactor and a fluorimetric detector allowed to properly record both photoinduced and native excitationemission fluorescence matrices (EEPIFMs and EEFMs, respectively). The obtained third-order liquid chromatography data were chemometrically processed with the multivariate curve resolution-alternating least-squares model. The sensitivity of the overall analytical method was enhanced by a very simple solid-phase extraction with C18 membranes, to be able to successfully apply it to natural water samples tested as real

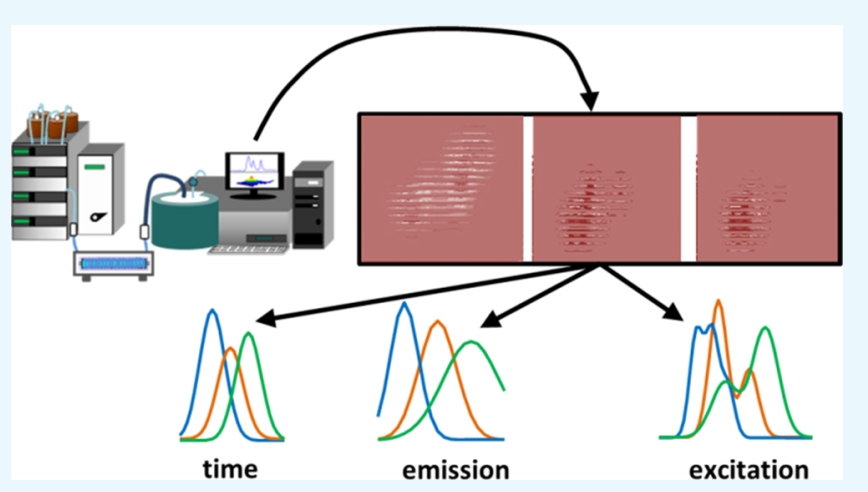
matrices. Favorable detection limits for the investigated pollutants, ranging from 0.02 to $0.27 \mathrm{ng} \mathrm{mL}$, were attained, with relative prediction errors between 2 and 7\%. Since the studied samples contain uncalibrated interferents, the applied strategy achieves the second-order advantage. Implications regarding the potential achievement of the third-order advantage are discussed.
\end{abstract}

\section{INTRODUCTION}

Relevant advantages of multiway calibration from different types of analytical signals have been widely discussed in the literature. ${ }^{1-5}$ It is worth mentioning the following benefits: (1) analytes can be quantitated in the presence of uncalibrated interferents (second-order advantage), ${ }^{6}$ (2) sample pretreatment is greatly simplified, and only pure analyte calibration sets are needed, and (3) selectivity and sensitivity are significantly increased. ${ }^{7}$ Specifically, third-order/four-way calibration possesses the additional benefit of the so-called "third-order advantage", which refers to its ability of resolving compounds with collinear profiles. ${ }^{8-10}$ Third-order/four-way data can be obtained, for example, from excitation-emission fluorescence matrices (EEFMs) as a function of liquid chromatographic (LC) elution time. ${ }^{11}$ Although different strategies have been proposed to record this type of data, an easy way for generating EEFMs during the chromatographic run (e.g., online measurement) has been recently proposed. ${ }^{10}$ The approach consisted in reducing the linear flow rate (LFR) to increase the width of each chromatographic peak. Thus, EEFMs were measured without significant variations of the local analyte concentration when changing the excitation wavelength for EEFM collection. This reduction of the LFR, without modifying the volumetric flow rate (VFR), was achieved by fitting a larger diameter connecting tube between the column outlet and the fluorimetric detector. ${ }^{10}$ Consequently, many matrices per chromatographic peak, without dependence between the data in the excitation and time modes, were successfully registered online. ${ }^{11}$

In the present work, following this concept and with the purpose of measuring excitation-emission photoinduced fluorescence matrices (EEPIFMs) of contaminants that do not exhibit native signals, additionally to a larger diameter connecting tube, a postcolumn photoreactor constituted by a tube coiled to a UV lamp was introduced.

The studied analytes included agrochemicals and emerging pollutants representative of therapeutic drugs, which are potentially present in environmental samples and with adverse ecological and human health effects. ${ }^{12-16}$ The investigated agrochemicals, whose structures are shown in Figure 1, were rimsulfuron [RIM; 1-(4,6-dimethoxypyrimidin-2-yl)-3-(3-ethylsulfonyl pyridin-2-yl)sulfonylurea; herbicide], fuberidazole [FBZ; 2-(2-furyl)-1H-benzimidazole; fungicide], and carbaryl [CBL; 1-naphthyl methylcarbamate; insecticide]. The emerging pollutants were represented by naproxen $[\mathrm{NAP} ;(S)-(+)-6$ methoxy- $\alpha$-methyl-2-naphthalene acetic acid; non-steroidal anti-inflammatory], albendazole [ALB; methyl-[(5-propylthio)-1H-benzimidazol-2-yl] carbamate; antihelminthic agent]

Received: September 19, 2018

Accepted: November 8, 2018

Published: November 20, 2018 
<smiles>CCOS(=O)(=O)c1cccnc1S(=O)(=O)NC(=O)Nc1nc(OC)cc(OC)n1</smiles>
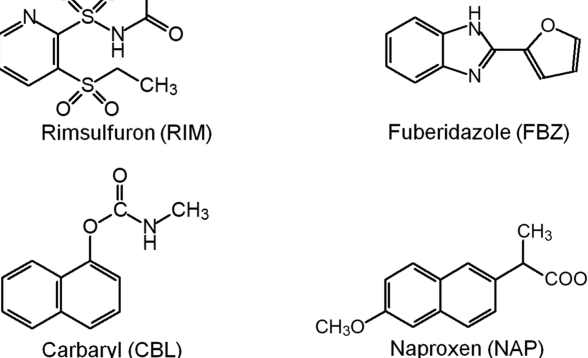

Fuberidazole (FBZ)
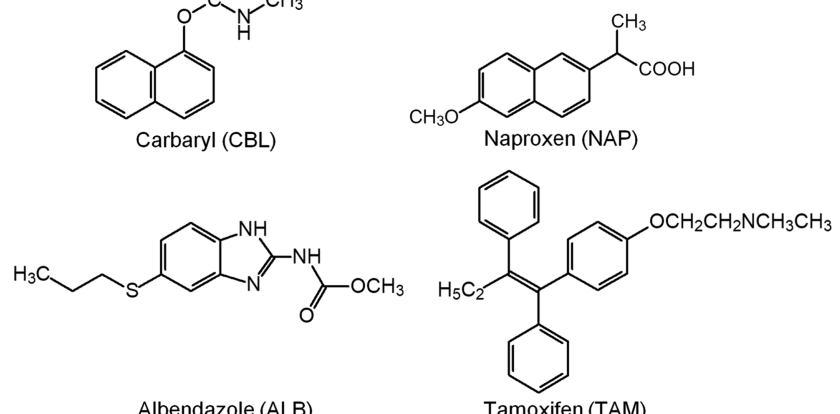

Albendazole (ALB)

Tamoxifen (TAM)

Figure 1. Structures of the studied analytes.

and tamoxifen [TAM; trans-1-(4- $\beta$-dimethylaminoethoxyphenyl)-1,2-diphenyl-1-butene; anticancer agent].

Some of the selected compounds display native fluorescence, whereas others only show emission signals upon UV irradiation; these properties were useful in the present context for their quantitation. As will be demonstrated, the obtained LC-EEFM and LC-EEPIFM third-order data could not be arranged as a four-way array complying with the quadrilinearity condition, and thus multivariate curve resolution-alternating least squares (MCR-ALS) ${ }^{17}$ was applied for data treatment.

The challenges presented by the selected system within the framework of green analytical chemistry are analyzed and discussed, namely, (1) the simultaneous quantitation of pollutants with different spectroscopic properties, (2) the optimization of the experimental conditions considering the analytical goals, (3) the correct measurement of proper online third-order chromatographic data, and (4) the successful resolution of a system with severe spectral overlapping and high collinearity in the chromatographic profiles.

\section{RESULTS AND DISCUSSION}

Luminescent Properties of Analytes. Among the studied analytes, RIM and TAM exhibit virtually no native fluorescence. However, both show fluorescence bands upon irradiation. The sulfonylurea bridge in the RIM molecule is photochemically cleaved on both sides of the carbonyl group yielding a nitrogen-containing heterocycle and an aryl sulfonamide, which are thought to be responsible for the observed fluorescence, although the structures of breakdown photoproducts have not been yet characterized (Figure 2A). ${ }^{18}$ On the other hand, after UV irradiation of TAM, a main fluorescent phenanthrene derivative is formed by photocyclization, with maxima at ca. 365 and $390 \mathrm{~nm}$ (Figure 2B). ${ }^{19,20}$

The remaining four analytes are naturally fluorescent, presenting specific behaviors after UV irradiation. As has already been reported, the strong fluorescence of both NAP and FBZ decrease after being photoirradiated, ${ }^{21,22}$ and the photochemical decomposition of CBL in acetonitrile (ACN), induced by continuous UV radiation, follows a degradation

(A)
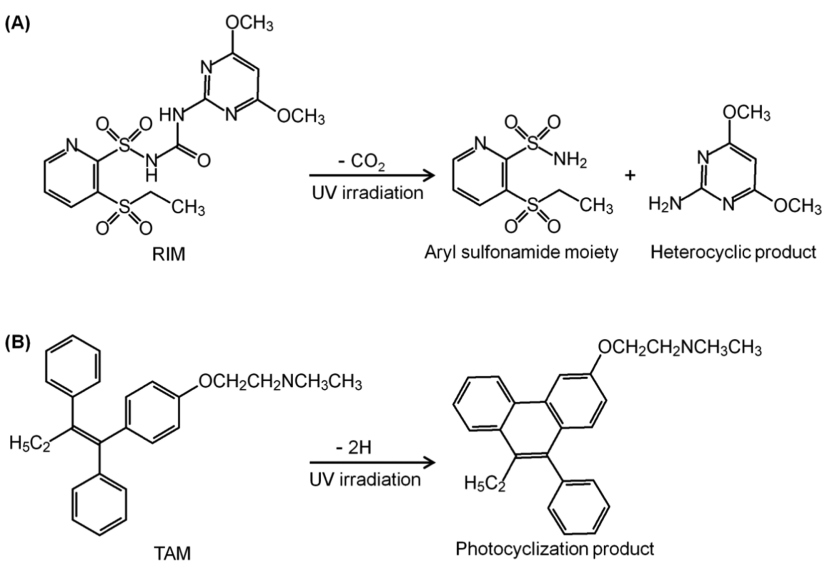

Figure 2. Photoinduced reactions suggested for RIM (A) and TAM (B).

pathway different from that reported in aqueous medium producing phthalic anhydride, 1,4-naphtalenedione, and 1naphthol. ${ }^{23}$ However, the fluorescence intensity of these latter three analytes does not change over time in our experimental conditions, indicating that they are not being degraded, at least to a significant degree. Depending on the solvent, ALB displays fluorescence with maxima in the range of $440-470 \mathrm{~nm},{ }^{24}$ and after irradiation under the studied conditions a photoproduct is formed, emitting at $310 \mathrm{~nm}$.

In conclusion, RIM, TAM, and ALB were evaluated through the EEPIFMs collected for their photoproducts, whereas for $\mathrm{NAP}, \mathrm{FBZ}$, and $\mathrm{CBL}$ the native fluorescence signals were employed.

Optimization of Experimental Conditions. The most relevant experimental variables affecting both chromatographic and spectroscopic profiles are interdependent. They were optimized to achieve the following goals: (1) a certain resolution in a relatively short time, (2) a minimum solvent consumption, and (3) promotion of photoproduct formation without affecting the signals of the analytes whose native fluorescence could decrease with irradiation.

Furthermore, a suitable number of excitation-emission matrices should be registered during the elution of the sample (e.g., 6-8 matrices for each chromatographic band), and they should have a proper number of excitation and emission data points for adequate processing. In fact, in a typical experiment, when trying to measure EEFMs of a moving sample, the excitation spectrum of each analyte changes in shape as a function of measurement time. ${ }^{11}$ As previously demonstrated, this mutual dependence between excitation and time profiles can be avoided by decreasing the LFR through the increase of the flowing tube diameter connecting the column outlet with the detector. ${ }^{10}$ In the present work, a postcolumn photoreactor and an additional tube between the photoreactor and the cell were inserted. In this way, the LFR was decreased at a constant VFR, allowing the collection of a suitable number of EEFMs without significantly increasing the total analysis time.

The photoreactor dimensions and the VFR were modified with the purpose of achieving maximum intensities of the PIF signals, taking into account that (1) the signal for the nonfluorescent analytes RIM and TAM increased with the irradiation time and then remained approximately constant and (2) the irradiation time depends on the photoreactor length and the VFR. Two photoreactor lengths $(250$ and $500 \mathrm{~cm})$ and VFRs in the range 0.4 and $1 \mathrm{~mL} \mathrm{~min}^{-1}$ were probed. It was 


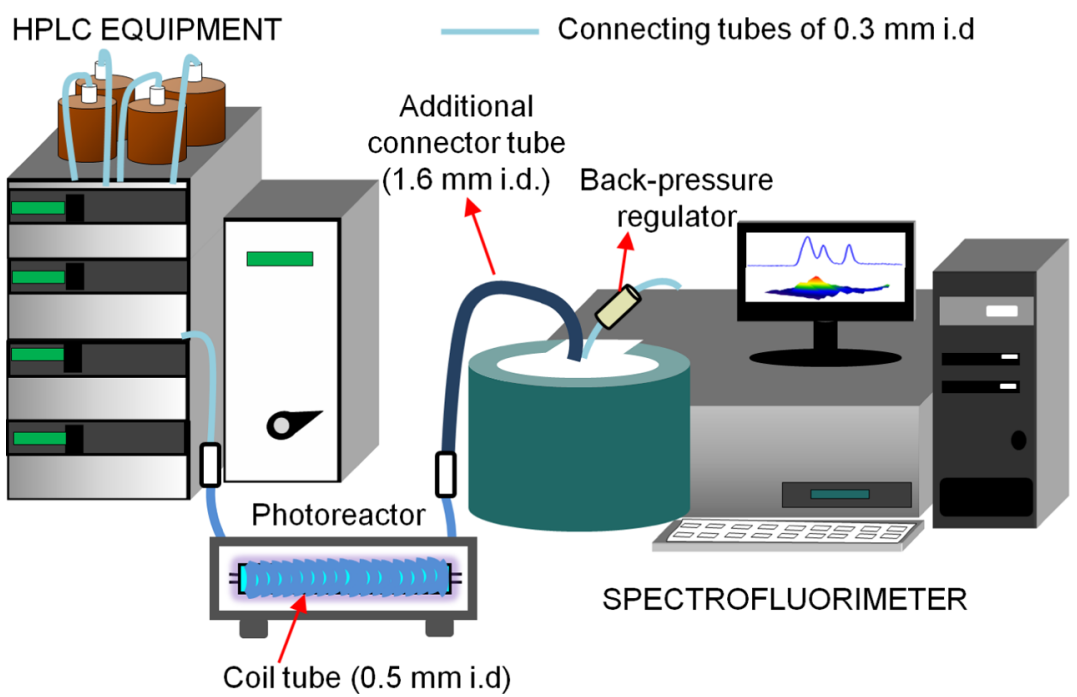

Figure 3. Schematic representation of experimental equipment

Table 1. Experimental Conditions

\begin{tabular}{|c|c|c|c|c|c|}
\hline \multicolumn{2}{|r|}{ chomatographic run } & \multicolumn{2}{|c|}{ photoproduct generation } & \multicolumn{2}{|c|}{ matrix measurement } \\
\hline mobile phase & $\begin{array}{l}\text { ACN/acetate-acetic acid buffer } 20 \mathrm{mM}(\mathrm{pH}=5.5) \text {. Gradient: } t(0) \\
=35 \% \mathrm{ACN}, t(4,5 \mathrm{~min})=100 \% \mathrm{ACN}\end{array}$ & lamp & $\begin{array}{l}8 \text { W germicide } \\
\text { UV lamp }\end{array}$ & scanning speed & $19200 \mathrm{~nm} \mathrm{~min}-1$ \\
\hline column & C8 reverse-phase, $4.6 \times 30 \mathrm{~mm}^{2}, 5 \mu \mathrm{m}$ particle size & coil tube ${ }^{b}$ & $500 \times 0.05 \mathrm{~cm}^{2}$ & time range & $\begin{array}{l}\text { from } 0 \text { to } 12 \mathrm{~min} \text {, } \\
\text { each } 0.28 \mathrm{~min}\end{array}$ \\
\hline $\operatorname{VFR}^{a}$ & $0.7 \mathrm{~mL} \mathrm{\operatorname {min } ^ { - 1 }}$ & $\begin{array}{l}\text { connector } \\
\text { tube }^{b}\end{array}$ & $16 \times 0.16 \mathrm{~cm}^{2}$ & emission range & $\begin{array}{l}\text { from } 310 \text { to } 400 \mathrm{~nm} \text {, } \\
\text { each } 4 \mathrm{~nm}\end{array}$ \\
\hline $\begin{array}{l}\text { injection } \\
\text { volume }\end{array}$ & $50 \mu \mathrm{L}$ & & & $\begin{array}{l}\text { excitation } \\
\text { range }\end{array}$ & $\begin{array}{l}\text { from } 227 \text { to } 277 \mathrm{~nm} \text {, } \\
\text { each } 2.5 \mathrm{~nm}\end{array}$ \\
\hline \multirow{5}{*}{$\begin{array}{l}\text { column } \\
\text { temperature }\end{array}$} & $35^{\circ} \mathrm{C}$ & & & excitation slit & $10 \mathrm{~nm}$ \\
\hline & & & & emission slit & $20 \mathrm{~nm}$ \\
\hline & & & & $\mathrm{PMV}^{c}$ & $900 \mathrm{~V}$ \\
\hline & & & & $\begin{array}{l}\text { cell-holder } \\
\text { temperature }\end{array}$ & $20^{\circ} \mathrm{C}$ \\
\hline & & & & $\begin{array}{l}\text { matrices per } \\
\text { run }\end{array}$ & 38 \\
\hline
\end{tabular}

${ }^{a}$ Volumetric flow ratio. ${ }^{b}$ Poly(tetrafluoroethylene) (PTFE) tube. ${ }^{c}$ Photomultiplier voltage.

corroborated that a $500 \mathrm{~cm}$ photoreactor length and a VFR of $0.7 \mathrm{~mL} \mathrm{m^{-1 }}$ produced the most sensitive signals without altering the signals of the remaining analytes. Different lengths, from 10 to $50 \mathrm{~cm}$, of the additional tube of $1.6 \mathrm{~mm}$ internal diameter, were tested, and the final dimensions were set for obtaining a time width at least of $2 \mathrm{~min}$.

The composition of the mobile phase (solvents and $\mathrm{pH}$ ) has an influence on the retention time as well as on both the extension of the photoreaction and the fluorescence intensity. ${ }^{25}$ Because the fluorescence signals of the studied analytes in methanol were less intense than in $\mathrm{ACN}$, mobile phases containing different ratios of $\mathrm{ACN}$ and buffer solution were tested. The selected buffer was an acetate/acetic acid solution of $\mathrm{pH}=5.5$, since our exploratory experiments proved that a slightly acidic $\mathrm{pH}$ produced satisfactory signals.

A schematic diagram of the employed equipment is shown in Figure 3, and a summary of the experimental conditions applied for the determination of the evaluated analytes is given in Table 1. Notice the additional connecting tube having an internal diameter, which is larger than the remaining tubes, and the presence of a back-pressure regulator, which prevents bubbles and improves baseline stability.
Figure 4A shows the excitation and emission spectra of the analytes after photoirradiation and their chromatographic behavior under the selected working conditions. The spectral overlapping and co-elution among the calibrated analytes are clear in this figure. It is apparent that the situation would be further complicated in real samples with unknown constituents.

The increasing complexity from a pure analyte sample and a real matrix can be visualized in Figure 5 through the contour plots of selected EEFMs at different chromatographic elution time.

Validation Samples. In addition to the mutual dependence between excitation and time profiles of LC-EEFM and LC-EEPIFM third-order data measured in real-time with a single equipment, elution time shifts or shape changes may occur between successive chromatographic runs. ${ }^{11}$ In the present system, loss of quadrilinearity due to lack of reproducibility in elution times was detected, and therefore MCR-ALS was conveniently applied with matrix superaugmentation in the temporal direction. ${ }^{17}$

For MCR-ALS data processing, superaugmented matrices were built with the three-dimensional data arrays for each of the 12 validation samples and all of the calibration samples, 
(A)
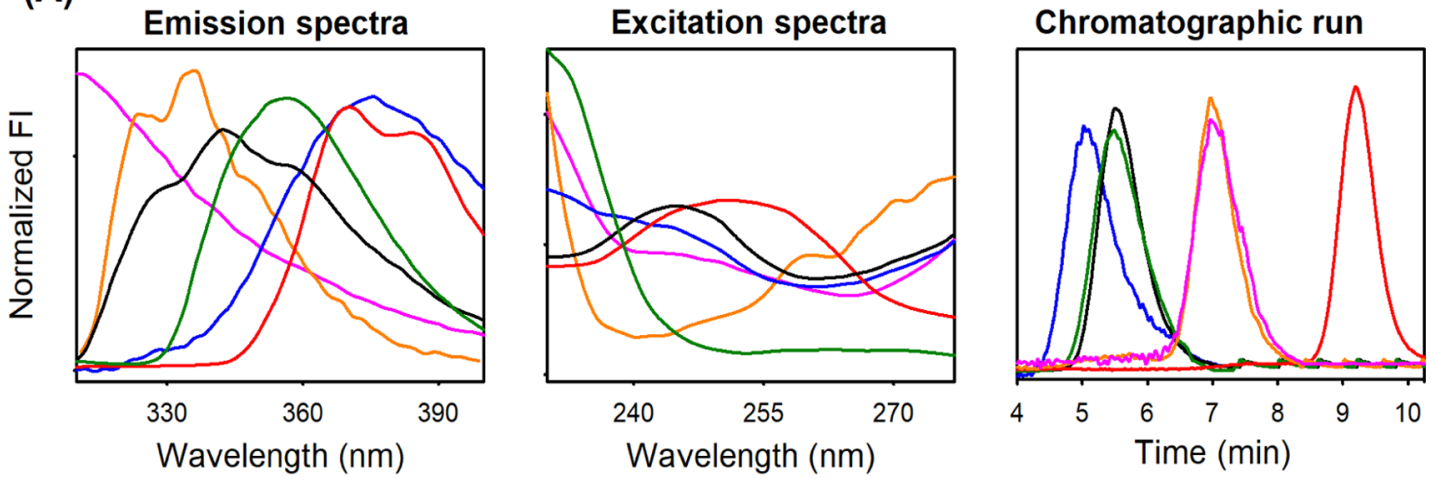

(B)
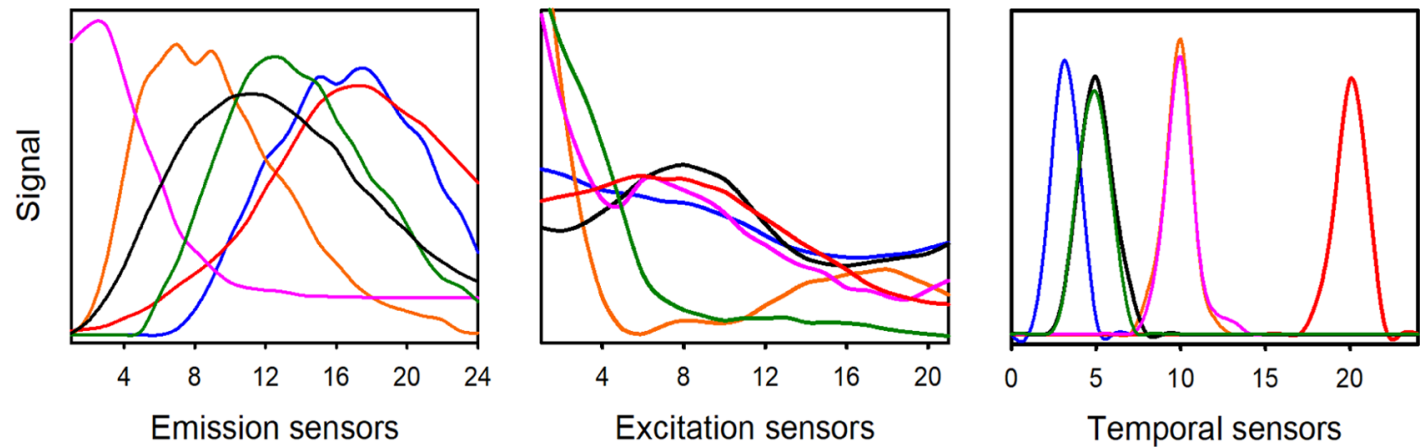

Figure 4. (A) Experimental profiles (as indicated) for RIM (blue), FBZ (black), CBL (orange), NAP (green), ALB (pink), and TAM (red) after postcolumn irradiation. (B) Profiles retrieved by MCR-ALS after processing a validation sample. Blanks were omitted for clarity. All intensities are normalized to unit length.
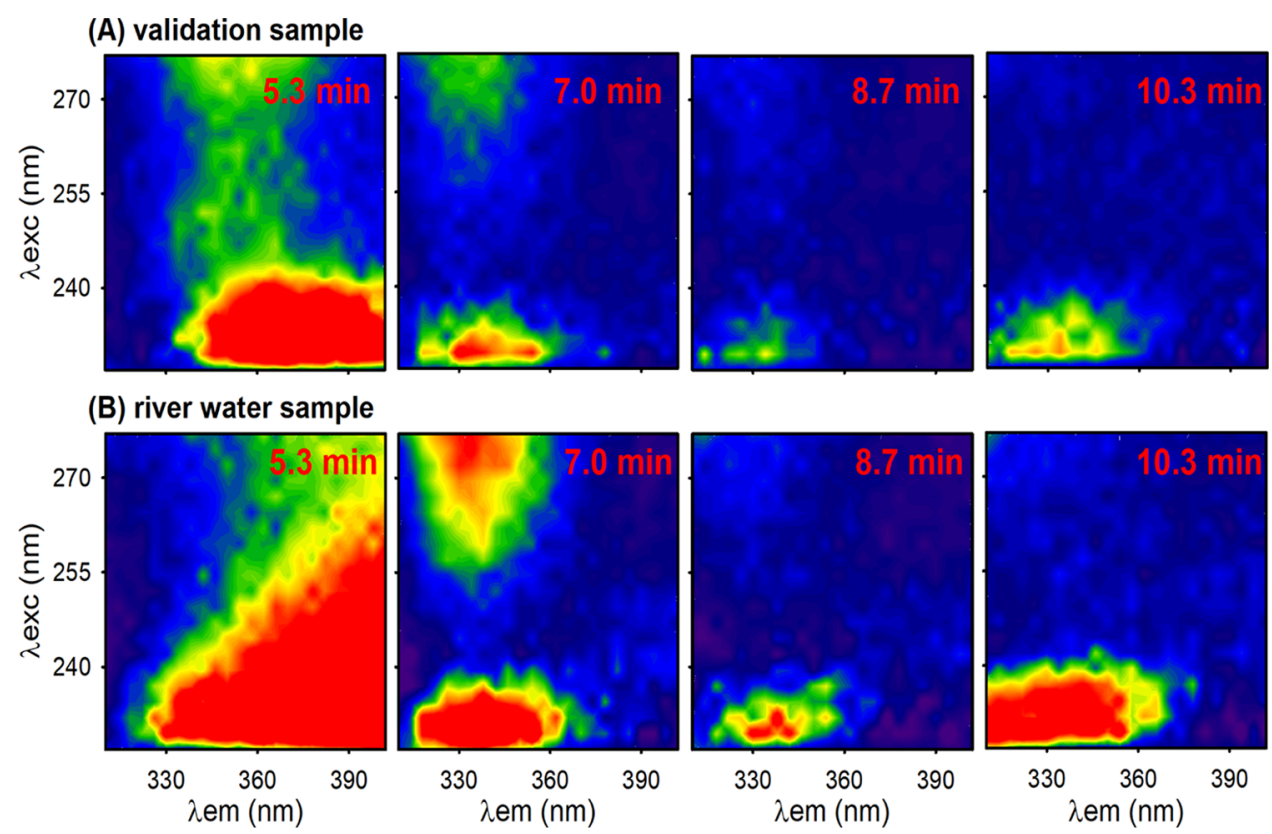

Figure 5. Selected excitation-emission fluorescence contour plots during a chromatographic run as indicated for a validation sample (A) and for a river sample added with the studied analytes (B).

after unfolding them to matrices whose modes were (1) the elution time mode and (2) the concatenations of excitation and emission modes, as explained in the Supporting Information. Baseline correction of each submatrix of the superaugmented matrix was performed using a homemade routine based on asymmetric least-squares. ${ }^{26}$ Nine compo- nents, corresponding to the six analytes and three background signals, were estimated by applying principal component analysis. ${ }^{17}$ The profiles employed as initial approximations for starting MCR-ALS were estimated as the purest variables in the concatenated excitation-emission spectral domain. Non-negativity in both augmented and nonaugmented modes, 

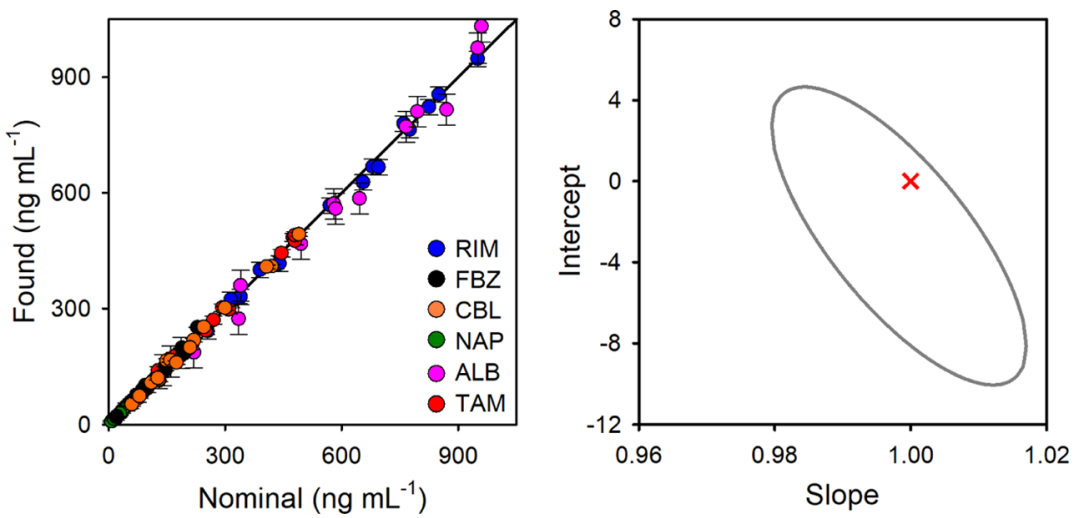

Figure 6. Plot of predicted concentration of the evaluated endocrine disruptors as a function of the nominal values in validation samples and the corresponding elliptical joint region (at 95\% confidence level) for the slope and intercept of the regression of the data. The red cross marks the theoretical (intercept $=0$, slope $=1$ ) point.

unimodality constraint in the time profile, and area correlation and correspondence between components and samples were applied. ${ }^{27}$ After convergence of the ALS optimization, the nonaugmented profiles were refolded to retrieve individual excitation and emission profiles, which are adequate for spectral interpretation. Analytes were then identified by their spectral profiles, and quantitation was performed using each of the univariate calibration curves. The latter was built from analyte scores (areas of the elution time profiles) for the calibration samples. The test analyte score was then interpolated in the calibration line (see Supporting Information for additional details).

The good quality of the MCR-ALS-recovered spectral and temporal profiles can be appreciated in Figure 4B, and Figure 6 displays the satisfactory prediction results for the evaluated analytes in validation samples. The latter figure also shows the elliptical joint confidence region for the slope and intercept of the plot, predicted as a function of nominal concentrations, allowing for a statistical analysis of the predictions. ${ }^{28}$ Because the obtained elliptical domains include the theoretically predicted values for the slope and the intercept (slope $=1$ and intercept $=0$ ), the accuracy of the methodology is confirmed.

A relevant challenge of the analyzed system is the almost complete co-elution between the pairs FBZ-NAP and CBLALB (Figure 4A). However, this high degree of collinearity was successfully overcome by the applied MCR-ALS model (Figure 4B). As in other similar systems processed by thirdorder/four-way models, the resolution of highly collinear profiles supports the achievement of the third-order advantage. $^{8-10}$ Figures of merit, calculated according to the suggestion of Bauza et al., ${ }^{29}$ and statistical indicators for validation samples are shown in Table 2 . The good resolution achieved is in agreement with the reasonably high selectivity values quoted in the latter table.

It is important to notice that in second-order chromatographic data with fluorescent detection at a constant excitation wavelength, the latter should be selected as a compromise among the excitation maxima of the various analytes. In contrast, in the presently discussed third-order calibration process, the excitation wavelength is scanned in an appropriate range during the measurements. This increases the method sensitivity because each analyte is irradiated at a number of wavelengths, including its spectral maximum.
Table 2. Figures of Merit and Statistical Indicators for the Studied Analytes in Validation Samples

$\begin{array}{lllllll} & \text { RIM } & \text { FBZ } & \text { CBL } & \text { NAP } & \text { ALB } & \text { TAM } \\ \begin{array}{l}\text { analytical sensitivity } \\ (\text { ng mL }\end{array} & 0.12 & 0.75 & 0.19 & 0.56 & 0.05 & 0.43 \\ \text { selectivity } & 0.39 & 0.50 & 0.45 & 0.57 & 0.42 & 0.52 \\ \text { LOD }\left(\mathrm{ng} \mathrm{mL}^{-1}\right)^{a} & 11 & 4.5 & 11 & 6.2 & 23 & 8.2 \\ \text { LOQ }\left(\mathrm{ng} \mathrm{mL}^{-1}\right)^{b} & 34 & 14 & 33 & 19 & 70 & 25 \\ \text { RMSEP }\left(\mathrm{ng} \mathrm{mL}^{-1}\right)^{c} & 16 & 7 & 9 & 2 & 36 & 7 \\ \text { REP }(\%)^{d} & 3 & 6 & 4 & 5 & 7 & 3\end{array}$

${ }^{a}$ Limit of detection. ${ }^{b}$ Limit of quantitation. ${ }^{c}$ Root-mean square error of prediction. ${ }^{d}$ Relative error of prediction.

Real Samples. The usefulness of the proposed method was tested by analyzing natural water susceptible to contamination by organic pollutants. Although collection proceeded near urban areas, the analytes were not detected in these samples, and a recovery study by spiking them with the studied analytes at four different fortification levels was performed.

The European Community has stated that maximum admissible concentration levels for each pesticide and for the total amount in drinking water are 0.1 and $0.5 \mathrm{ng} \mathrm{mL}^{-1}$, respectively. ${ }^{30}$ On the other hand, although the presence in natural water of NAP, TAM, and ALB is not regulated by international agencies, levels in the order of sub-part-perbillions are frequently found for these compounds in aquatic bodies, reaching parts per billion in contaminated areas. NAP is one of the most commonly found pharmaceutical pollutants in water and as recent examples we remark NAP levels up to $0.55 \mathrm{ng} \mathrm{mL}^{-1}$ and up to $6.3 \mathrm{ng} \mathrm{mL}^{-1}$ detected in surface water and sewage treatment plants, respectively, of urbanized zones of Italy, Spain, USA, and Canada. ${ }^{13,15,21}$ Although information related with environmental concentrations of ALB is limited, ${ }^{16}$ it is known that levels of anthelmintics in water samples are mostly in the $\mathrm{ng} \mathrm{\textrm {L } ^ { - 1 }}$ and $\mathrm{ng} \mathrm{mL}^{-1}$ range. ${ }^{31}$ Very low concentrations of TAM have been measured in different surface water $\left(<0.07 \mathrm{ng} \mathrm{mL}{ }^{-1}\right),{ }^{15,32,33}$ but higher levels have been found in sewage treatment plants of China $(0.224 \mathrm{ng}$ $\left.\mathrm{mL}^{-1}\right)^{34}$ and in a river water of the U.K. $\left(0.212 \mathrm{ng} \mathrm{mL}^{-1}\right){ }^{35}$ On the basis of the above considerations, the sensitivity of the present method for water real samples was improved using a preconcentration step by employing C18 membrane solidphase extraction (SPE). 
Table 3. Recovery Studies of Mixtures of the Studied Analytes in Spotted Water Samples (S) and the Corresponding Statistical Results $^{a}$

\begin{tabular}{|c|c|c|c|c|c|c|c|c|c|c|c|c|}
\hline & \multicolumn{2}{|c|}{ RIM } & \multicolumn{2}{|c|}{ FBZ } & \multicolumn{2}{|c|}{ CBL } & \multicolumn{2}{|c|}{ NAP } & \multicolumn{2}{|c|}{ ALB } & \multicolumn{2}{|c|}{ TAM } \\
\hline & taken & found $^{b}$ & taken & found $^{b}$ & taken & found $^{b}$ & taken & found $^{b}$ & taken & found $^{b}$ & taken & found $^{b}$ \\
\hline$S 1^{c}$ & 0.25 & $0.18(4)$ & 0.58 & $0.55(1)$ & 0.84 & $0.81(3)$ & 0.26 & $0.29(1)$ & 0.82 & $0.72(8)$ & 0.89 & $0.92(3)$ \\
\hline $\mathrm{S} 2^{d}$ & 1.38 & $1.42(4)$ & 0.08 & $0.10(1)$ & 0.16 & $0.17(2)$ & 0.08 & $0.07(1)$ & 3.60 & $4.05(9)$ & 1.45 & $1.39(2)$ \\
\hline $\mathrm{S} 3^{e}$ & 1.55 & $1.62(4)$ & 0.55 & $0.54(1)$ & 1.82 & $1.86(2)$ & 0.37 & $0.34(2)$ & 2.20 & $2.30(9)$ & 0.70 & $0.66(4)$ \\
\hline$S 4^{f}$ & 2.70 & $2.77(4)$ & 0.16 & $0.10(1)$ & 1.96 & $1.82(3)$ & 0.15 & $0.12(1)$ & 0.90 & $1.06(8)$ & 0.25 & $0.25(2)$ \\
\hline$t^{g}$ & 0.74 & & 0.85 & & 0.66 & & 0.53 & & 1.15 & & 0.80 & \\
\hline $\mathrm{LOD}^{h}$ & 0.12 & & 0.02 & & 0.07 & & 0.02 & & 0.27 & & 0.06 & \\
\hline $\mathrm{LOQ}^{h}$ & 0.36 & & 0.07 & & 0.21 & & 0.07 & & 0.8 & & 0.17 & \\
\hline RMSEP $^{h}$ & 0.06 & & 0.04 & & 0.07 & & 0.03 & & 0.25 & & 0.04 & \\
\hline $\mathrm{REP}^{h}$ & 2 & & 4 & & 4 & & 7 & & 6 & & 2 & \\
\hline
\end{tabular}

${ }^{a}$ Concentrations are given in $\mathrm{ng} \mathrm{mL}{ }^{-1} .{ }^{b}$ Standard deviations, in the last digit, are given between parentheses. ${ }^{c}$ Underground water from Santa Rosa city (La Pampa, Argentina). ${ }^{d}$ Underground water from Funes city (Santa Fe, Argentina). ${ }^{e}$ Underground water from Andino village (Santa Fe, Argentina). ${ }^{f}$ River water from Ibarlucea village (Santa Fe, Argentina). ${ }^{g}$ Calculated $t$ values when a paired Student's $t$-test is applied at $95 \%$ confidence level and $n-1$ degrees of freedom, $t_{\text {crit }}=2.15$. ${ }^{h}$ See Table 2.

Table 3 displays the recovery results after spiking water samples with different analyte amounts at four concentration levels. The significance was tested employing the Student $t$ test: the null hypothesis corresponds to the ideal $100 \%$ recovery. ${ }^{28}$ The obtained $t$ values for $n-1$ degrees of freedom ( $n$ is the number of concentration levels) at a $p$ value of 0.05 for the degree of confidence are lower than the corresponding critical values, implying that the proposed method is suitable for the analyte quantitation in the studied samples.

Table 3 also includes the statistical results corresponding to quantitation in real water matrices. Limits of detection and quantitation reflect the benefits of the preconcentration and the possibility of determining the studied analytes at sub-partper-billion levels. Besides, the relative error of prediction is not affected by the fact that real matrices are being studied. The advantages of the proposed method in comparison with traditional chromatographic ones are especially noticeable in these real samples, where both simple experimental and chemometric treatments are required for obtaining highquality results.

\section{CONCLUSIONS}

This work reports a novel strategy to obtain online third-order chromatographic data for the simultaneous quantitation of fluorescent analytes and those with fluorescent photoproducts.

The introduction of both a photoreactor and a connecting tube of large diameter between the column and the spectrofluorimeter allowed the efficient collection, in parallel with the chromatographic procedure, of excitation-emission fluorescence and photoinduced fluorescence matrices. Thus, chromatographic third-order data are obtained online, in less than $10 \mathrm{~min}$, with the concomitant advantages of this type of data. Due to the favorable characteristics of high sensitivity, selectivity, collinearity resolution, and saving of experimental time, the method represents a better alternative than both univariate- and second-order calibration. It may also be preferable to offline chromatographic third-order calibration methods. According to the properties of the studied data, MCR-ALS was selected for chemometric processing. This latter model showed a very good performance to quantitate the analytes even in the presence of unknown constituents. Finally, this report is a new example of the power and applicability of high-order calibration in complex system, maintaining the principles of the green analytical chemistry.

\section{EXPERIMENTAL SECTION}

Reagents and Materials. RIM and NAP were obtained from Fluka (St. Louis), and FBZ was purchased from Riedel-de Haën (Seelze, Germany). CBL, ALB, and TAM were obtained from Sigma-Aldrich (St. Louis). Acetic acid was provided by Sintorgán (Buenos Aires, Argentina) and sodium acetate by Cicarelli (San Lorenzo, Argentina). ACN was obtained from Merck (Darmstadt, Germany). Milli-Q water (Millipore, Bedford) was used in all experiments. Stock solutions of analytes in the range $200-500 \mathrm{mg} \mathrm{L}^{-1}$ were prepared in ACN. From these solutions, more diluted ACN solutions (around 5$25 \mathrm{mg} \mathrm{L}^{-1}$ ) were obtained.

Instrumentation and Procedure. Chromatographic measurements were performed on an Agilent 1200 liquid chromatograph (Agilent Technologies, Waldbronn, Germany) equipped with a quaternary pump and a thermostated column compartment set at $35^{\circ} \mathrm{C}$. A Rheodyne valve with a $50.0 \mu \mathrm{L}$ loop was employed to inject the sample on to a Restek Pinnacle II-C8, $5 \mu \mathrm{m}$ particle size, $30 \mathrm{~mm}$ length, $4.6 \mathrm{~mm}$ internal diameter column (Restek, Bellefonte). A photoreactor, consisting of a poly(tetrafluoroethylene) (PTFE) tube network $(5 \mathrm{~m} \times 0.5 \mathrm{~mm}$ i.d.) coiled around a tubular $8 \mathrm{~W}$ low-pressure mercury lamp, was used for the postcolumn photoirradiation. This light source emits the known mercury spectrum, including the most intense line in the UV region at $254 \mathrm{~nm}$, and because of the low power rating of this light source, no cooling in the photoreactor was required. A PTFE tube $(16 \mathrm{~cm})$ of $1.6 \mathrm{~mm}$ i.d. was used to connect the photoreactor with the detector. PTFE tubing of $0.3 \mathrm{~mm}$ i.d. was used for all of the remaining connections. The data were collected using the software HP ChemStation for LC Rev. HP 1990-1997.

The chromatographic analysis was performed using a mixture of $20 \mathrm{mmol} \mathrm{L}^{-1}$ of sodium acetate/acetic acid buffer pH 5.5 (solvent A) and ACN (solvent B) as mobile phase. An elution gradient program was employed: linear gradient from $65 \% \mathrm{~A}: 35 \% \mathrm{~B}$ to $100 \% \mathrm{~B}, 0-4.5 \mathrm{~min}$, isocratic elution with $100 \%$ B until $12 \mathrm{~min}$. The mobile phase composition was brought back to the initial conditions, and after a reconditioning period of $4 \mathrm{~min}$, the next sample was injected. Samples were filtered through $0.22 \mu \mathrm{m}$ nylon membranes 


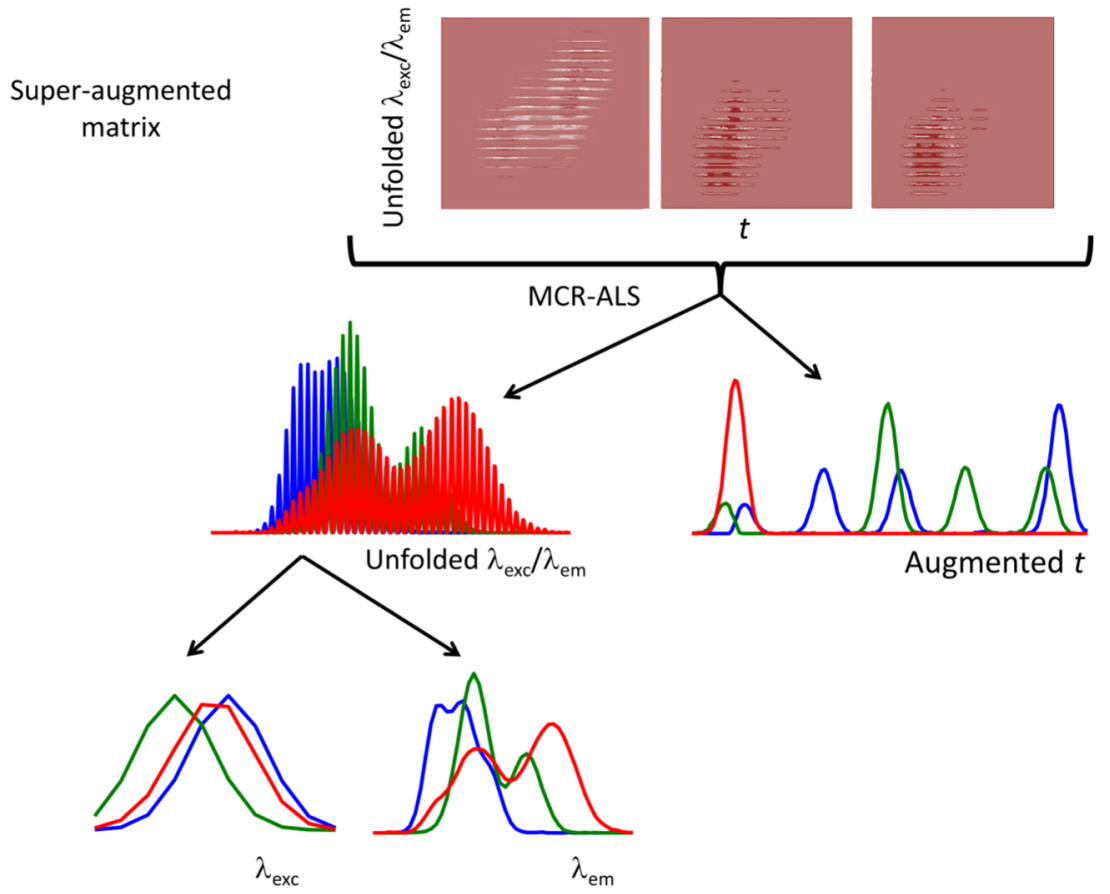

Figure 7. Schematic representation of MCR-ALS model to third-order LC-EEFM/EEPIFM data processing.

before injection. The VFR was maintained at $0.7 \mathrm{~mL} \mathrm{~min}^{-1}$. An Agilent Cary-Eclipse luminescence spectrometer (Agilent Technologies, Waldbronn, Germany) was used as detector, employing an $8 \mu \mathrm{L}$ quartz flow cell (Starna, CA) of $1 \mathrm{~mm}$ optical path. The excitation and emission slit widths were, respectively, 10 and $20 \mathrm{~nm}$, the photomultiplier sensitivity was $900 \mathrm{~V}$, and spectral scanning speed of $19200 \mathrm{~nm} \mathrm{~min}^{-1}$ was applied. The cell temperature was regulated at $20{ }^{\circ} \mathrm{C}$ using a thermostatic bath (Cole-Parmer, IL).

Chromatographic data were collected from 2 to $12.5 \mathrm{~min}$ each $0.28 \mathrm{~min}$, and EEFMs were recorded from 310 to $402 \mathrm{~nm}$ each $4 \mathrm{~nm}$ (emission) and from 227 to $277 \mathrm{~nm}$ each $2.5 \mathrm{~nm}$ (excitation). The reading of each EEFM required a time of approximately $17 \mathrm{~s}$, allowing to register 38 EEFMs for each sample. In this way, data arrays of size $38 \times 24 \times 21$ for temporal, emission spectral, and excitation spectral modes were, respectively, generated.

Calibration and Validation Samples. A calibration set of 19 samples was prepared (Table S1). Some (12) of these samples corresponded to the concentrations provided by the Plackett-Burman design, one sample was a blank solution, and the remaining six samples included each pure analyte at the mean concentration. The analytes were evaluated at the following concentration ranges: $0-1000 \mathrm{ng} \mathrm{mL^{-1 }}$ for both RIM and ALB, $0-500 \mathrm{ng} \mathrm{mL}^{-1}$ for TAM, $0-250 \mathrm{ng} \mathrm{mL}^{-1}$ for both FBZ and CBL, and $0-100 \mathrm{ng} \mathrm{mL}^{-1}$ for NAP. A validation set was prepared employing concentrations different than those used for calibration and following a random design (Table S2). Calibration and validation samples were prepared immediately before their use by taking appropriate aliquots of diluted ACN solutions, placing them in $5.00 \mathrm{~mL}$ volumetric flasks, drying the solvent under nitrogen, and completing to the mark with buffer (sodium acetate/acetic acid, $\mathrm{pH} 5.5$ )/ACN (65:35, v/v) solution.

Water Sample Procedure. Well and river water samples were prepared by spiking them with standard solutions of the studied analytes, obtaining concentration levels in the range
$0.2-3 \mathrm{ng} \mathrm{mL} \mathrm{m}^{-1}$. These samples were filtered through $0.45 \mu \mathrm{m}$ pore size nylon membranes. Samples were subjected to SPE with $\mathrm{C} 18$ disks. Each disk was previously conditioned with 0.5 $\mathrm{mL}$ of methanol and $1 \mathrm{~mL}$ of ultrapure water. Aliquots of 100 $\mathrm{mL}$ were passed through the disks. After elution of the retained organic constituents with methanol, the solvent was evaporated with nitrogen, the residue was reconstituted with $400 \mu \mathrm{L}$ of mobile phase, and the obtained solutions were subjected to the same chromatographic analysis as the validation samples. The preconcentration factor was 1:250.

Chemometric Algorithm and Data Treatment. A brief description of the MCR-ALS theory applied to third-order data is given in the Supporting Information. Figure 7 shows a graphical illustration of the analyzed superaugmented data matrix for a hypothetical system formed by two analytes and one interferent and the MCR-ALS decomposition process.

Software. MCR-ALS was implemented in MATLAB $\mathrm{R} 2012 \mathrm{a}$ and was applied using the graphical interface MVC3, ${ }^{36}$ which is an integrated MATLAB toolbox for thirdorder/four-way calibration. It is freely available on the Internet. $^{37}$

\section{ASSOCIATED CONTENT}

\section{S Supporting Information}

The Supporting Information is available free of charge on the ACS Publications website at DOI: 10.1021/acsomega.8b02439.

Theory of the MCR-ALS model as applied to thirdorder liquid chromatographic data with excitationemission matrix detection (Tables S1 and S2) (PDF)

\section{AUTHOR INFORMATION}

\section{Corresponding Authors}

*E-mail: ibanez@iquir-conicet.gov.ar (G.A.I.).

*E-mail: escandar@iquir-conicet.gov.ar (G.M.E.). 


\section{ORCID $\odot$}

Alejandro C. Olivieri: 0000-0003-4276-0369 Graciela M. Escandar: 0000-0001-8308-6433

\section{Notes}

The authors declare no competing financial interest.

\section{ACKNOWLEDGMENTS}

The financial support from Universidad Nacional de Rosario (Project BIO 237), CONICET (Consejo Nacional de Investigaciones Cientificas y Técnicas, Project PIP 0163), and ANPCyT (Agencia Nacional de Promoción Cientifica y Tecnológica, Project PICT 2016-1122) is gratefully acknowledged. R.B.P.V. thanks CONICET for a postdoctoral fellowship.

\section{REFERENCES}

(1) Escandar, G. M.; Olivieri, A. C. A road map for multi-way calibration models. Analyst 2017, 142, 2862-2873.

(2) Olivieri, A. C.; Escandar, G. M. Practical Three-Way Calibration; Elsevier: Waltham, 2014.

(3) Data Handling in Science and Technology, Fundamentals and Analytical Applications of Multiway Calibration; Muñoz de la Peña, A.; Goicoechea, H. C.; Escandar, G. M.; Olivieri, A. C., Eds.; Elsevier: Amsterdam, 2015; Vol. 29.

(4) Jalalvand, A. R.; Goicoechea, H. C.; Rutledge, D. N. Applications and challenges of multi-way calibration in electrochemical analysis. TrAC, Trends Anal. Chem. 2017, 87, 32-48.

(5) Parastar, H.; Tauler, R. Multivariate curve resolution of hyphenated and multidimensional chromatographic measurements: a new insight to address current chromatographic challenges. Anal. Chem. 2014, 86, 286-297.

(6) Booksh, K. S.; Kowalski, B. R. Theory of analytical chemistry. Anal. Chem. 1994, 66, 782A-791A.

(7) Olivieri, A. C. Analytical figures of merit: from univariate to multiway calibration. Chem. Rev. 2014, 114, 5358-5378.

(8) Kang, C.; Wu, H. L.; Xie, L. X.; Xiang, S. X.; Yu, R. Q. Direct quantitative analysis of aromatic amino acids in human plasma by four-way calibration using intrinsic fluorescence: exploration of thirdorder advantages. Talanta 2014, 122, 293-301.

(9) Carabajal, M. D.; Arancibia, J. A.; Escandar, G. M. Excitationemission fluorescence-kinetic data obtained by Fenton degradation. Determination of heavy-polycyclic aromatic hydrocarbons by fourway parallel factor analysis. Talanta 2017, 165, 52-63.

(10) Carabajal, M. D.; Arancibia, J. A.; Escandar, G. M. On-line generation of third-order liquid chromatography-excitation-emission fluorescence matrix data. Quantitation of heavy-polycyclic aromatic hydrocarbons. J. Chromatogr. A 2017, 1527, 61-69.

(11) Montemurro, M.; Siano, G. G.; Alcaráz, M. R.; Goicoechea, H. C. Third order chromatographic-excitation-emission fluorescence data: advances, challenges and prospects in analytical applications. TrAC, Trends Anal. Chem. 2017, 93, 119-133.

(12) Nougadère, A.; Reninger, J. C.; Volatier, J. L.; Leblanc, J. C. Chronic dietary risk characterization for pesticide residues: A ranking and scoring method integrating agricultural uses and food contamination data. Food Chem. Toxicol. 2011, 49, 1484-1510.

(13) Castiglioni, S.; Davoli, E.; Riva, F.; Palmiotto, M.; Camporini, P.; Manenti, A.; Zuccato, E. Data on occurrence and fate of emerging contaminants in a urbanised area. Data Brief 2018, 17, 533-543.

(14) Riva, F.; Castiglioni, S.; Fattore, E.; Manenti, A.; Davoli, E.; Zuccato, E. Monitoring emerging contaminants in the drinking water of Milan and assessment of the human risk. Int. J. Hyg. Environ. Health 2018, 221, 451-457.

(15) Wilkinson, J.; Hooda, P. S.; Barker, J.; Barton, S.; Swinden, J. Occurrence, fate and transformation of emerging contaminants in water: An overarching review of the field. Environ. Pollut. 2017, 231, 954-970.
(16) Horvat, A. J. M.; Petrović, M.; Babić, S.; Pavlović, D. M.; Ašperger, D.; Pelko, S.; Mance, A. D.; Kaštelan-Macan, M. Analysis, occurrence and fate of anthelmintics and their transformation products in the environment. TrAC, Trends Anal. Chem. 2012, 31, 61-84.

(17) Tauler, R.; Maeder, M.; de Juan, A. Multiset Data Analysis: Extended Multivariate Curve Resolution. In Comprehensive Chemometrics; Brown, S.; Tauler, R.; Walczak, B., Eds.; Elsevier: Oxford, 2009; pp 473-505.

(18) Coly, A.; Aaron, J. J. Photochemically-induced fluorescence determination of sulfonylurea herbicides using micellar media. Talanta 1999, 49, 107-117.

(19) Nieder, M.; Jaeger, H. Quantification of tamoxifen and Ndesmethyltamoxifen in human plasma by high-performance liquid chromatography, photochemical reaction and fluorescence detection, and its application to biopharmaceutic investigations. J. Chromatogr. B: Biomed. Sci. Appl. 1987, 413, 207-217.

(20) Šalamoun, J.; Macka, M.; Nechvátal, M.; Matoušek, M.; Knesel, L. Identification of products formed during UV irradiation of tamoxifen and their use for fluorescence detection in high performance liquid chromatography. J. Chromatogr. A 1990, 514, $179-187$.

(21) Arany, E.; Szabó, R. K.; Apáti, L.; Alapi, T.; Ilisz, I.; Mazellier, P.; Dombi, A.; Gajda-Schrantz, K. Degradation of naproxen by UV, VUV photolysis and their combination. J. Hazard. Mater. 2013, 262, 151-157.

(22) Melo, M. J.; Pina, F.; Maçanita, A. L.; Melo, E. C.; Herrmann, C.; Förster, R.; Koch, H.; Wamhoff, H. Photochemistry of 2-(2Furyl)-benzimidazole (Fuberidazole). Z. Naturforsch. B 1992, 47, 1431-1437.

(23) Yousef, Y. A.; El-Khatib, F. Photodegradation of carbaryl in acetonitrile solution. Spectrosc. Lett. 2007, 40, 573-582.

(24) Küçükkolbaşi, S.; Gündüz, B.; Kılıç, E. Development of a spectrofluorimetric method for determination of albendazole in tablets. Anal. Lett. 2008, 41, 104-118.

(25) Arancibia, J. A.; Escandar, G. M. Second-order chromatographic photochemically-induced fluorescence emission data coupled to chemometric analysis for the simultaneous determination of urea herbicides in the presence of matrix co-eluting compounds. Anal. Methods 2014, 6, 5503-5511.

(26) Eilers, P. H. C.; Currie, I. D.; Durbán, M. Fast and compact smoothing on large multidimensional grids. Comput. Stat. Data Anal. 2006, 50, 61-76.

(27) de Oliveira Neves, A. C.; Tauler, R.; de Lima, K. M. G. Area correlation constraint for the MCR-ALS quantification of cholesterol using EEM fluorescence data: a new approach. Anal. Chim. Acta 2016, 937, 21-28.

(28) González, A. G.; Herrador, M. A.; Asuero, A. G. Intralaboratory testing of method accuracy from recovery assays. Talanta 1999, 48, 729-736.

(29) Bauza, M. C.; Ibañez, G. A.; Tauler, R.; Olivieri, A. C. Sensitivity equation for quantitative analysis with multivariate curve resolution-alternating least-squares: theoretical and experimental approach. Anal. Chem. 2012, 84, 8697-8706.

(30) Directive 2006/11/CE of the European Parliament and of the Council of February 15th 2006, published in the Official Journal of the European Journal on March 4th 2006.

(31) Cacho, C.; Turiel, E.; Pérez-Conde, C. Molecularly imprinted polymers: An analytical tool for the determination of benzimidazole compounds in water simples. Talanta 2009, 78, 1029-1035.

(32) Xie, H. Occurrence, ecotoxicology, and treatment of anticancer agents as water contaminants. J. Environ. Anal. Toxicol. S 2012, 2, 111.

(33) Thomas, K. V.; Hilton, M. J. The occurrence of selected human pharmaceutical compounds in UK estuaries. Mar. Pollut. Bull. 2004, $49,436-444$

(34) Yang, Y.; Fu, J.; Peng, H.; Hou, L.; Liu, M.; Zhou, J. L. Occurrence and phase distribution of selected pharmaceuticals in the 
Yangtze Estuary and its coastal zone. J. Hazard. Mater. 2011, 190, 588-596.

(35) Roberts, P. H.; Thomas, K. V. The occurrence of selected pharmaceuticals in wastewater effluent and surface waters of the lower Tyne catchment. Sci. Total Environ. 2006, 356, 143-153.

(36) Mazivila, S. J.; Bortolato, S. A.; Olivieri, A. C. MVC3_GUI: a MATLAB graphical user interface for third-order multivariate calibration. An upgrade including new multiway models. Chemom. Intell. Lab. Syst. 2018, 173, 21-29.

(37) www.iquir-conicet.gov.ar/descargas/mvc3.zip (accessed Sep, 2018). 